\title{
National Survey of Pharmacokinetic Services in Saudi Arabia: Perceptions and Barriers of Service Implementations
}

\author{
Yousef Ahmed Alomi* iD, The \\ Former General Manager of General Adminis- \\ tration of Pharmaceutical Care and Head, \\ National Clinical pharmacy, and Pharmacy \\ Practice and Pharmacy R \& D Administration, \\ $\mathrm{MOH}$, Riyadh, Saudi Arabia. \\ Ban Abdullah Aldosary, Pharmaceutical Care \\ Department, Al-Amel Mental City, Ministry of \\ Health, Riyadh, Saudi Arabia. \\ Rasha Abdelsalam Elshenawy, BCS. Pharm. \\ BCPS (AQ-ID), CPHQ, M.SC., TQM (AUC), SIDP, \\ CEO of FADIC, Ministry of Health, Makkah, \\ Saudi Arabia.
}

\section{Correspondence:}

Dr. Yousef Ahmed Alomi, The Former General Manager of General Administration of Pharmaceutical Care, The Former Head, National Clinical pharmacy and pharmacy practice, The Former Head, Pharmacy R \& D Administration, Ministry of Health Riyadh, SAUDI ARABIA

Phone no: +966504417712

E-mail:yalomi@gmail.com
Received: 22-01-2019;

Accepted: 17-03-2019

Copyright: (c) the author(s), publisher and licensee International Journal of Pharmacology and Clinical Sciences. This is an open-access article distributed under the terms of the Creative Commons Attribution Non-Commercial License, which permits unrestricted non-commercial use, distribution, and reproduction in any medium, provided the original work is properly cited.

This is an open access article distributed under the terms of the Creative Commons Attribution-NonCommercial-ShareAlike 4.0 License

Access this article online

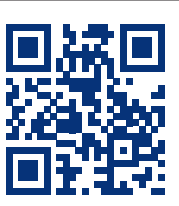

www.ijpcs.net

DOI:

10.5530/ijpcs.2019.8.33

\begin{abstract}
Objectives: To explore the pharmacokinetic services at the Ministry of Health (MOH) hospitals in Saudi Arabia with an emphasis on perceptions and barriers of service implementation. Methods: This is a 2-month cross-sectional national survey of pharmacokinetic services with a focus on pharmacy management and resources at $\mathrm{MOH}$ hospitals in Saudi Arabia. The study consisted of two parts: the first part collected demographic information and the second part consisted of 43 questions divided into three domains. The questions were derived from the American Society of Health-System Pharmacists (ASHP) guidelines and from the literature. We used 5-point Likert response scale system with close-ended questions to obtain responses. An electronic questionnaire was distributed to the coordinators of the clinical pharmacy services or drug information centers at $\mathrm{MOH}$ hospitals and it analyzed the perceptions and barriers of pharmacokinetic service implementations section through the Survey Monkey system. Results: A total of 43 hospital pharmacies responded to the questionnaire, with the response rate of $86 \%$. The majority of pharmacokinetic services were provided to the adult patients $(37(86.05 \%))$ followed by the pediatric and geriatric patients (19 (44.19\%) and $13(30.23 \%)$, respectively) with most of the responding hospitals having less than 20 beds $(23(53.5 \%))$. The categories with most of the barriers of pharmacokinetic service implementation were lack of knowledge $(20(64.52 \%))$, lack of pharmacokinetic education (16 (51.61\%)) and lack of an expert pharmacist in pharmacokinetic services (16 (51.61\%)). Most of the responders agreed that clinical pharmacokinetic services were necessary for hospitals (23 (53.5\%)). The responders agreed that the clinical pharmacist through pharmacokinetic services had a positive financial impact and cost avoidance on healthcare system (23 (53.5\%)). Most of the responders stated that pharmacokinetic services improve the safety and efficacy of patient care $(33(89.2 \%))$. Most of the responders agreed that the pharmacokinetic services improved patients' clinical outcome (33 (89.2\%)) and prevented drug-related problems $(33(89.2 \%))$, whereas few of the pharmacokinetic services were provided only $10(29.4 \%)$ over 24 hr per day. Conclusion: Despite the positive attitude of hospital management toward pharmacokinetic services, there was a lack of education and training regarding the same at $\mathrm{MOH}$ hospitals in Saudi Arabia. Revision of strategic planning of pharmacokinetic services with regard to their improvement and implementation are required at all $\mathrm{MOH}$ hospitals in Saudi Arabia.
\end{abstract}

Keywords: pharmacokinetics, Perceptions, Barriers Ministry of Health, Saudi Arabia.

\section{INTRODUCTION}

Clinical Pharmacokinetic Services (CPSs) are essential components of the drug Therapy Monitoring (TDM) in hospital setting. Several researchers have investigated the outcome of CPSs in various hospitals. These studies have shown that pharmacokinetic services may improve the clinical outcome of the patient, decrease drug-related problems, decrease length of hospital stay and avoid unnecessary drug therapy cost. ${ }^{[1-9]}$ However, to the best of our knowledge, there are no studies conducted on the perception, feeling and attitude of the CPSs or on barriers of pharmacokinetic service implementations in the Gulf or Middle Eastern countries or in other countries. ${ }^{[10]}$ Therefore, in this study, we aimed to explore the pharmacist's perception of barriers of implementation of pharmacokinetic services at $\mathrm{MOH}$ hospitals in Saudi Arabia.

\section{METHODS}

This is a 2-month cross-sectional national survey of pharmacokinetic services with a focus on pharmacy management and resources at $\mathrm{MOH}$ hospitals in Saudi Arabia. The study consisted of two part: the first part collected demographic information and the second part consisted of 43 questions divided into four domains. The questions were derived from the ASHP guidelines and from the literature. ${ }^{[11-14]}$ The domains were grouped as follows: Pharmacy management and resources, medication prescribing and dispensing, drug monitoring and pharmacy education and perceptions and barrier of service implementations. We used the 5-point Likert response scale system with close-ended questions to obtain responses. The questionnaire was prepared in an electronic format and was distributed to the coordinators of the CPSs or drug information centers at $\mathrm{MOH}$ hospitals. It analyzed the perceptions and 


\begin{tabular}{|l|c|c|}
\hline Table 1: Demographic information about hospital. \\
\hline \multicolumn{1}{|c|}{ Number of beds at your hospital } & Response Count & Response Percent \\
\hline$<50$ & 3 & $7.0 \%$ \\
\hline $50-99$ & 6 & $14.0 \%$ \\
\hline $100-199$ & 10 & $23.3 \%$ \\
\hline $200-299$ & 14 & $32.6 \%$ \\
\hline $300-399$ & 6 & $14.0 \%$ \\
\hline $400-499$ & 4 & $9.3 \%$ \\
\hline $500-599$ & 0 & $0.0 \%$ \\
\hline or $>600$ & 0 & $0.0 \%$ \\
\hline Medical City & 3 & $7.0 \%$ \\
\hline Answered question & 43 & \\
\hline Skipped question & 0 & Response Percent \\
\hline The hospital accreditation & Response Count & $39.53 \%$ \\
\hline CIBAHI & 17 & $25.58 \%$ \\
\hline Joint Commotion USA & 11 & $0.00 \%$ \\
\hline Canada & 0 & $16.28 \%$ \\
\hline Saudi commission of health accreditation & 7 & $18.60 \%$ \\
\hline Non & 8 & \\
\hline Answered question & 43 & \\
\hline Skipped question & 0 & \\
\hline
\end{tabular}

\begin{tabular}{|c|c|c|}
\hline Academic Qualification (s): & Response Count & Response Percent \\
\hline Diploma. Pharmacy & 4 & $9.30 \%$ \\
\hline Bsc. Pharmacy & 22 & $51.16 \%$ \\
\hline Master of Science & 12 & $27.91 \%$ \\
\hline Doctor of Pharmacy & 11 & $25.58 \%$ \\
\hline Two years Residency (R1) & 1 & $2.33 \%$ \\
\hline Three years Residency (R2) & 0 & $0.00 \%$ \\
\hline Ph. D & 1 & $2.33 \%$ \\
\hline M.B.A. & 1 & $2.33 \%$ \\
\hline Answered question & 43 & \\
\hline Skipped question & 0 & \\
\hline Board of Pharmaceutical Specialty & Response Count & Response Percent \\
\hline Board Certified Ambulatory Care Pharmacist (BCACP) & 0 & $0.0 \%$ \\
\hline Board Certified Critical Care Pharmacist (BCCCP) & 0 & $0.0 \%$ \\
\hline Board Certified Nuclear Pharmacist (BCNP) & 0 & $0.0 \%$ \\
\hline Board Certified Nutrition Support Pharmacist (BCNSP) & 0 & $0.0 \%$ \\
\hline Board Certified Oncology Pharmacist (BCOP) & 0 & $0.0 \%$ \\
\hline Board Certified Pediatric Pharmacy Specialist (BCPPS) & 0 & $0.0 \%$ \\
\hline Board Certified Pharmacotherapy Specialists (BCPS) & 0 & $0.0 \%$ \\
\hline Board Certified Psychiatric Pharmacist (BCPP) & 0 & $0.0 \%$ \\
\hline Non & 38 & $100.0 \%$ \\
\hline Other (please specify))) & 0 & $0.0 \%$ \\
\hline Answered question & 38 & \\
\hline Skipped question & 5 & \\
\hline Total years of Experiences in Pharmacokinetic services & Response Count & Response Percent \\
\hline$<1$ year & 4 & $9.3 \%$ \\
\hline 1 - 3 years. & 9 & $20.9 \%$ \\
\hline $4-6$ years. & 7 & $16.3 \%$ \\
\hline$=$ or $>6$ years. & 9 & $20.9 \%$ \\
\hline No experiences & 11 & $25.6 \%$ \\
\hline Other (please specify) & 3 & $7.0 \%$ \\
\hline Answered question & 43 & \\
\hline Skipped question & 0 & \\
\hline
\end{tabular}

barriers of service implementations through the Survey Monkey system.

\section{RESULTS}

A total of 43 hospital pharmacies responded to the questionnaire, with a response rate of $86 \%$. Majority of the hospitals responded had 200-299 beds (14 (32.6\%) and 100-199 beds $(10(23.3 \%))$. Most of the hospitals had accreditation from CBAHI (17 (39.53\%)) and from Joint Commotion USA (11 (25.59\%)) and $8(16.6 \%)$ hospitals had no accreditations (Table 1). The highest level of education of the responders was Bachelor Degree in Pharmacy (22 (51.2\%)), Master of Science (12 (27.91\%)) and Doctor of Pharmacy (11 (25.58\%)). Most of the responders had more than 6 years of experience in CPSs $(9$ (20.9\%)). None of the responders had accreditation from the Board of Pharmaceutical Specialties (Table 2). The majority of pharmacokinetic services were provided to the adult patients (37 (86.05\%)) followed by pediatric and geriatrics patients (19 (44.19\%) and 13 (30.23\%), respectively), with most of the responders having less than 20 beds (23 (53.5\%)). Most of the pharmacokinetic services were provided through the inpatient pharmacy $(27(62.79 \%))$ and outpatient pharmacy and discharge services (9 $(20.93 \%))$. Most of the hospital pharmacies (33 (76.7\%)) received less than 100 prescriptions for CPSs daily (Table 3 ). Most of the barriers to the implementation of pharmacokinetic services was lack of knowledge (20 (64.52\%)), lack pharmacokinetic education (16 (51.61\%)) and lack of expert pharmacist in pharmacokinetic services (16 (51.61\%)) (Table 4). Most of the responders agreed that CPSs were necessary for hospitals $(23$ (53.5\%)). The responders agreed that the clinical pharmacist through pharmacokinetic services had a positive financial impact and cost avoidance on the healthcare system $(23(53.5 \%))$. Most of the responders stated that pharmacokinetic services improved the safety and efficacy of patient care $(33(89.2 \%))$. Most of the responders also agreed that the pharmacokinetic services improved patient clinical outcome (33 (89.2\%)) and prevented drug-related problems (33 (89.2\%)), whereas few of the pharmacokinetic services provided only $10(29.4 \%)$ over 24 hrs per day (Table 5).

\section{DISCUSSION}

Although the $\mathrm{MOH}$ hospitals started providing the pharmacokinetic services from a long time ago, the program has not been extended to other hospital pharmacies in the KSA. This might be related to the perception of the pharmacist about the program, or might be due to the barriers existed which prevented 


\begin{tabular}{|l|c|c|}
\hline Table 3: General information of clinical pharmacokinetic services. \\
\hline No. of Beds covers Pharmacokinetic services & Response Count & Response Percent \\
\hline$<20$ & 23 & $53.5 \%$ \\
\hline $20-29$ & 3 & $7.0 \%$ \\
\hline $30-39$ & 0 & $0.0 \%$ \\
\hline $40-49$ & 1 & $2.3 \%$ \\
\hline $50-59$ & 4 & $9.3 \%$ \\
\hline $60-69$ & 3 & $7.0 \%$ \\
\hline $70-79$ & 0 & $0.0 \%$ \\
\hline $80-89$ & 1 & $2.3 \%$ \\
\hline $90-99$ & 3 & $7.0 \%$ \\
\hline$=$ or $>100$ & 5 & $11.6 \%$ \\
\hline Answered question & 43 & \\
\hline Skipped question & 0 & \\
\hline
\end{tabular}

The type of section they are
receiving Pharmacokinetics services at the hospital

\begin{tabular}{|c|c|c|}
\hline Discharge Patient & 9 & $20.93 \%$ \\
\hline Ambulatory care clinic & 5 & $11.63 \%$ \\
\hline Inpatient pharmacy & 27 & $62.79 \%$ \\
\hline Outpatient pharmacy & 9 & $20.93 \%$ \\
\hline Home care & 4 & $9.30 \%$ \\
\hline Critical Care & 1 & $2.33 \%$ \\
\hline Non & 9 & $20.93 \%$ \\
\hline Answered question & 43 & \\
\hline Skipped question & 0 & \\
\hline $\begin{array}{l}\text { The type of patients you service at } \\
\text { Pharmacokinetics services }\end{array}$ & Response Count & Response Percent \\
\hline Adults & 37 & $86.05 \%$ \\
\hline Pediatrics & 19 & $44.19 \%$ \\
\hline Geriatric & 13 & $30.23 \%$ \\
\hline Neonates & 11 & $25.58 \%$ \\
\hline Non & 6 & $13.95 \%$ \\
\hline Answered question & 43 & \\
\hline Skipped question & 0 & \\
\hline $\begin{array}{l}\text { The number of prescription needed for } \\
\text { pharmacokinetics services }\end{array}$ & Response Count & Response Percent \\
\hline$<100$ & 33 & $76.7 \%$ \\
\hline $100-199$ & 4 & $9.3 \%$ \\
\hline 200-299 & 3 & $7.0 \%$ \\
\hline 300-399 & 0 & $0.0 \%$ \\
\hline $400-499$ & 0 & $0.0 \%$ \\
\hline $500-599$ & 2 & $4.7 \%$ \\
\hline 600-699 & 0 & $0.0 \%$ \\
\hline 700-799 & 0 & $0.0 \%$ \\
\hline $800-899$ & 0 & $0.0 \%$ \\
\hline 900-999 & 0 & $0.0 \%$ \\
\hline$=$ or $>1000$ & 1 & $2.3 \%$ \\
\hline Answered question & 43 & \\
\hline Skipped question & 0 & \\
\hline
\end{tabular}

the implementation of the program. In this study, we explored the elements of perception or barriers during a national survey of pharmacokinetic services. According to the findings, perfect perception related to the benefit of the program, which prevent drugrelated problems and improved patient care. We could not compare this result with other studies since there are no studies conducted on the same and the program was not developed properly. This might be related to several barriers of implementation. we found that the common barrier was lack of knowledge and education of pharmacokinetic program. This shows that there is no short educational course or a long-term training program in the field of pharmacokinetic service. The results almost lower than what reported by another study, because the pharmacokinetic services established well developed than the site of the study research. ${ }^{[10]}$ In many instances, healthcare systems and organizations are not optimally collaborating with academic institutions. Several opportunities exist to optimize the partnership between academic institutes with the hospital. This will require a leadership that sets a direction and establishes performance targets that are measurable, meaningful and mandatory. First, however, collaboration is needed to generate innovation and achieve higher performance. Collaboration between academia and healthcare systems to continue educating the pharmacists and keep them updated with the recent advances in medications, pharmacokinetic properties and all about the TDM required for medications. The partnership can foster innovation by providing effective leadership, adopting new approaches to professional education and training and cultivating future innovators. To achieve a productive partnership, the partners must achieve a shared vision and collaborate in the education and training of pharmacists. ${ }^{[15]}$ Furthermore, the number of clinical or expert pharmacists specialized in pharmacokinetic services was diminished at $\mathrm{MOH}$ hospitals. This result could not be compared with other publications since no data exists in this regard. The General Administration of Pharmaceutical Care should include an emphasis on the removal of by increasing the number and type of education of pharmacokinetic courses and increase the quantity and quality of clinical pharmacists at $\mathrm{MOH}$ hospitals in KSA.

\section{CONCLUSION}

The implementation of CPSs was found to be perceived as excellent by the pharmacists at $\mathrm{MOH}$ institution in KSA. There was incomplete of the pharmacokinetic services at most of the hospitals because of missing the pharmacokinetic 


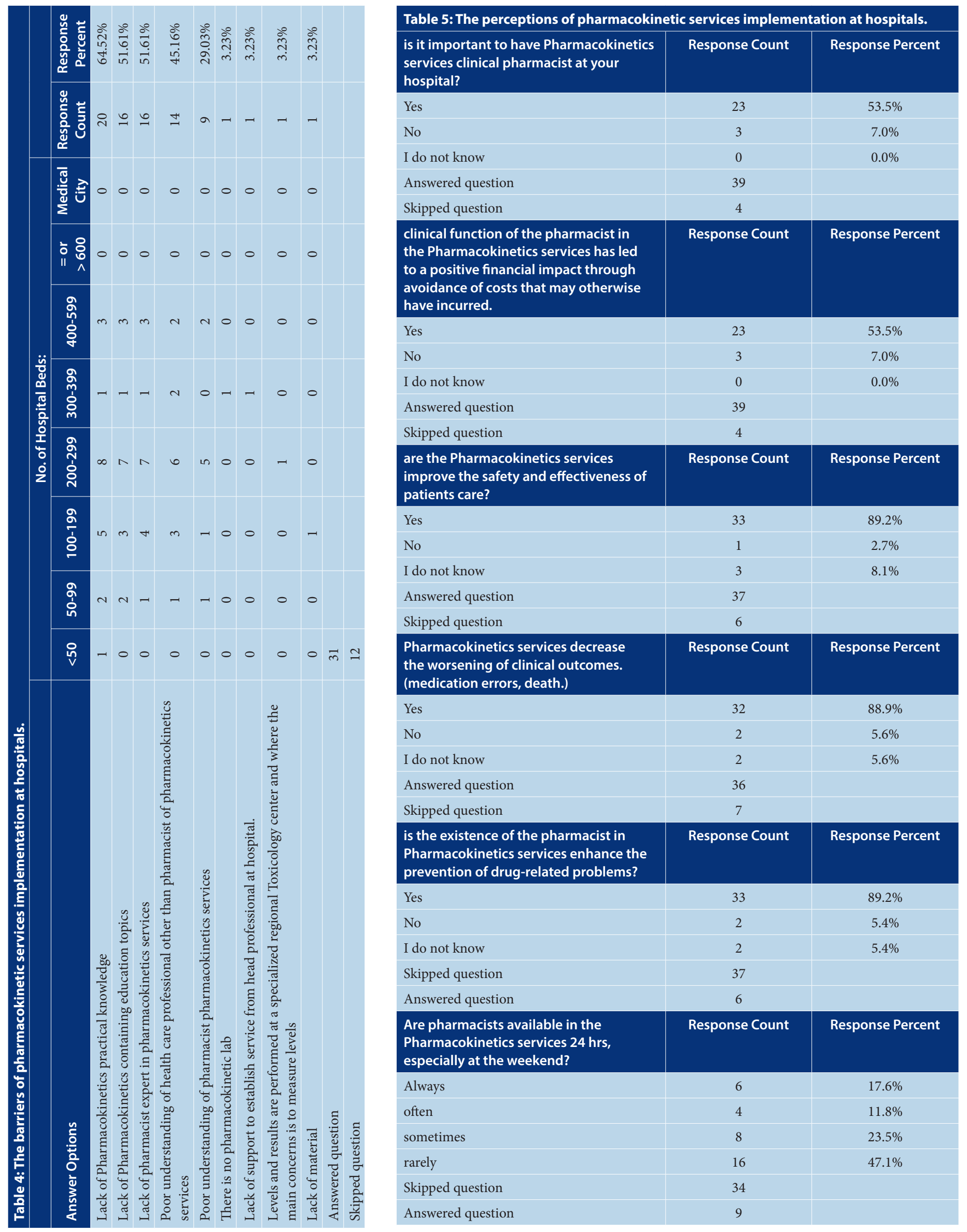


education and expert clinical pharmacokinetics pharmacist. It is necessary to overcome the barriers and improve the services and then improve the clinical outcome of patients and avoid the additional economic burden on the healthcare system at the $\mathrm{MOH}$ hospitals in KSA.

\section{ACKNOWLEDGMENT}

None.

\section{CONFLICTS OF INTEREST}

None.

\section{ABBREVIATIONS}

KSA: Kingdom of Saudi Arabia; MOH: Ministry of Health; CPS: Clinical Pharmacokinetic Services; ASHP: American Society of HealthSystem Pharmacists; TDM: Therapeutic drug monitoring.

\section{ORCID ID}

Yousef Ahmed Alomi https://orcid. org/0000-0003-1381-628X

\section{REFERENCES}

1. AlomiYA, Almudaiheem HY. Clinical And Economic Outcomes Of Pharmacist Intervention During Therapeutic Drug Monitoring Program In Saudi Arabia. Value Heal. 2016;19(7):A465-6.

2. Alomi YA, Almudaiheem HY. Clinical outcomes of pharmacokinetics services managed by pharmacist at Minitsery of Health in Saudi Arabia. Value Heal. 2017;A38.

3. Alomi YA, Almudaiheem HY. Clinical outcomes of Vancomycin therapeutic monitoring services at Minitsery of Health in Saudi Arabia. Value Heal. 2017; A42.

4. Bertino JS, Rodvold KA, Destache CJ. Cost Considerations in Therapeutic Drug Monitoring of Aminoglycosides. Clin Pharmacokinet. 1994; 26(1):71-81.

5. Destache CJ, Meyer SK, Bittner MJ, Hermann KG. Impact of a clinical pharmacokinetic service on patients treated with aminoglycosides: A costbenefit analysis. Ther Drug Monit. 1990;12(5):419-26.

6. Vožeh S. Cost-Effectiveness of Therapeutic Drug Monitoring. Clin Pharmacokinet. 1987;13(3):131-40.

7. Crist KD, Nahata MC, Ety J. Positive impact of a therapeutic Drug-Monitoring program on total aminoglycoside dose and cost of hospitalization. Ther Drug Monit. 1987;9(3):306-10,

8. Slaughter RL, Cappelletty DM. Economic impact of aminoglycoside toxicity and its prevention through therapeutic drug monitoring. Pharmaco Economics. 1998;(14):385-94.

9. Schumacher GE, Barr JT. Economic and Outcome Issues for Therapeutic Drug Monitoring in Medi- cine. Ther Drug Monit. 1998;20(5):539-42

10. Kheir N, Awaisu A, Gad H, Elazzazy S, Jibril F, Gajam M. Clinical pharmacokinetics: Perceptions of hospital pharmacists in Qatar about how it was taught and how it is applied. Int J Clin Pharm. 2015;37(6):1180-7.

11. Howard CE, Capers CC, Bess DT, Anderson RJ. Pharmacokinetics services in Department of Veterans Affairs medical centers. Am J Hosp Pharm. $1994 ; 51(13): 1672-5$.

12. Ab Rahman AF, Ahmed AHE, Mohamed IMI. A survey of therapeutic drug monitoring services in Malaysia. Saudi Pharm J. 2013;21(1):19-24

13. Alomi YA, Shorog E, Alshahrani A, Alasmary S, Alenazi $\mathrm{H}$, Almutairi $A$, et al. National Survey of Pharmacy Practice at $\mathrm{MOH}$ Hospitals in Saudi Arabia 2016-2017: Drug Monitoring and Patients Education. J Pharm Pract Community Med 2018;4(1s):s17-22.

14. Pedersen CA, Schneider PJ, Scheckelhoff DJ. ASHP national survey of pharmacy practice in hospital settings: Monitoring and patient education-2015. Am J Heal Pharm. 2016;73(17):1307-30.

15. Gubbins PO, Micek ST, Badowski M, Cheng J, Gallagher J, Johnson SG, et al. Innovation in clinical pharmacy practice and opportunities for academic-practice partnership. Pharmacotherapy. 2014:34(5):e45-54 